\title{
SISTEM PENGONTROL IRIGASI OTOMATIS MENGGUNAKAN MIKROKONTROLER ARDUINO UNO
}

\author{
Selamet Samsugi $^{*}$,), Zainabun Mardiyansyah ${ }^{2)}$, Andi Nurkholis ${ }^{3)}$ \\ 1) Program Studi Teknik Elektro, Fakultas Teknik dan Ilmu Komputer, Universitas Teknokrat Indonesia \\ Jl. ZA. Pagar Alam No.9 -11, Labuhan Ratu, Bandar Lampung, Indonesia 35132 \\ 2) Program Studi Teknik Komputer, Fakultas Teknik dan Ilmu Komputer, Universitas Teknokrat Indonesia \\ Jl. ZA. Pagar Alam No.9 -11, Labuhan Ratu, Bandar Lampung, Indonesia 35132 \\ 3) Program Studi Informatika, Fakultas Teknik dan Ilmu Komputer, Universitas Teknokrat Indonesia \\ Jl. ZA. Pagar Alam No.9 -11, Labuhan Ratu, Bandar Lampung, Indonesia 35132 \\ Email: ${ }^{1}$ s.samsugi@teknokrat.ac.id
}

\begin{abstract}
This study aims to design and implement a system that functions to open and close irrigation doors automatically. By using an automatic irrigation control system in order to facilitate farmers in controlling the entry of water in the irrigation flow. With the development of technology, the presence of sensors and microcontrollers makes it easier to make automatic irrigation controllers using an ultrasonic sensor. To read the water distance if the water distance is normal, the servo motor will open $180^{\circ}$. And if the water meets a height within a certain distance, the servo motor will move to close. As a water distance controller, the ultrasonic sensor reads the distance of the water that will be displayed on the LCD screen. The adapter functions as a supplier of AC current (220V) to DC (12V) which is used to flow the current to Arduino. In order for the irrigation flow to function automatically, an Arduino UNO R3 microcontroller is needed to receive data sent from the servo motor, ultrasonic sensor. So that this tool can be programmed to control the irrigation flow based on predetermined commands.
\end{abstract}

Keywords: Arduino UNO, control system, irigation

Abstrak
Penelitian bertujuan merancang dan
mengimplementasikan sebuah rangkaian yang
berfungsi untuk membuka dan menutup pintu irigasi
secara otomatis. Dengan menggunakan sistem
pengontrol irigasi otomatis agar dapat memudahkan
petani dalam mengontrol masukknya air dalam aliran
irigasi. Dengan berkembangnya teknologi, adanya
sensor dan mikrokontroler, mempermudah dalam
membuat alat pengontrol irigasi otomatis dengan
menggunakan sensor ultrasonik. Untuk membaca jarak
air apabila jarak air normal, maka motor servo akan
terbuka 180. Dan jika air mengalami ketinggian dalam
jarak yang tertentu, maka motor servo akan bergerak
menutup. Sebagai pengontrol jarak air, sensor
ultrasonik membaca jarakairyangakan ditampilkan ke
layar LCD. Adaptor berfungsi sebagai penyuplai arus

AC (220V) ke DC (12V) yang digunakan untuk mengaliri arus ke arduino. Agar aliran irigasi berfungsi secara otomatis, maka diperlukan mikrokontroler Arduino UNO R3 untuk menerima datadata yang dikirim dari motor servo, sensor ultrasonik. Sehingga alat ini bisa diprogram untuk melakukan pengontrolan pada aliran irigasi berdasarkan perintah yang telah ditentukan.

Kata Kunci: Arduino UNO, irigasi, sistem kontrol

\section{Pendahuluan}

Irigasi atau pengairan merupakan suatu usaha mendatangkan air dengan membuat bangunan atau saluran-saluran untuk ke sawah-sawah dengan cara teratur dan membuang air yang tidak diperlukan lagi, setelah air itu dipergunakan dengan sebaik-baiknya. Pengairan juga mengandung arti memanfaatkan dan menambah sumber air dalam tingkat tersedia bagi kehidupan tanaman. Apabila air terdapat berlebihan dalam tanah, maka perlu dilakukan pembuangan (drainase). Agar tidak mengganggu kehidupan tanaman. Sistem irigasi yang baik adalah salah satu faktor penentu keberhasilan dalam pertanian dan budidaya tanaman [1].

Air dikatakan tersedia bagi tanaman jika air yang berada dalam pori-pori tanah tersebut dapat diambil oleh akar tanaman. Kondisi seperti ini biasanya berada pada rentang air tersedia dimana dalam rentang ini juga dapat dihindari terjadinya perkolasi yang tidak diperlukan [2]. Pada umumnya, aliran air yang dilakukan petani dari pintu irigasi utama ke pintu irigasi percabangan berikutnya menggunakan sistem irigasi yang masih konvensional, oleh karena itu pemberian air irigasi sering tidak dapat dikendalikan sehingga berdampak pada ketidaksesuaian suplai air [3]. Dalam mengatasi hal tersebut, maka dibutuhkan alternatif untuk mengontrol masuk air ke pintu-pintu percabangan irigasi, yang dapat mempermudah pekerjaan manusia dengan memanfaatkan kemajuan teknologi [4][5][6] berupa sistem kontrol.

Sistem pengontrol irigasi sebelumnya telah banyak dikembangkan, yakni 1) sistem irigasi terkendali menggunakan jaringan nirkabel [7], irigasi curah otomatis 


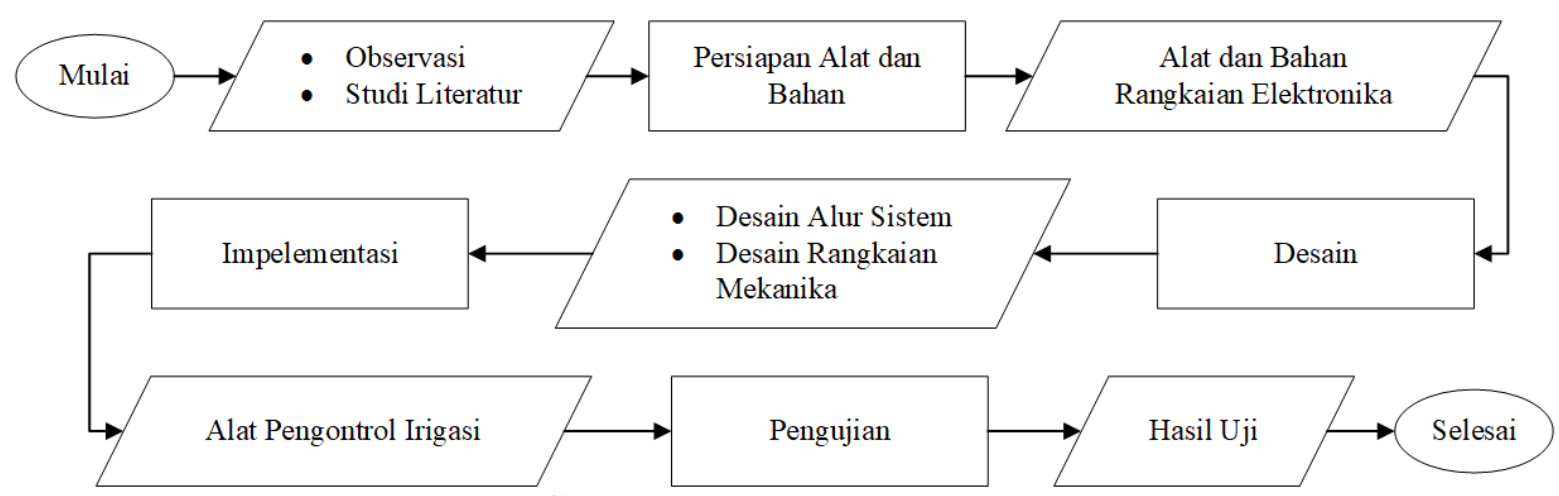

Gambar 1. Diagram alir penelitian

berbasis sistem pengendali mikro [2], dan 3) sistem kendali pintu air sorong yang berbasis serat kaca [8][9]. Sistem pengontrol juga dapat dikembangkan dengan memanfaatkan mikrokontroler Arduino UNO [10], yang kemudian dikombinasikan dengan sensor ultrasonik sebagai pendeteksi debit air.

Berdasarkan pemaparan yang telah dilakukan, maka penelitian ini mengembangkan sistem menggunakan mikrokontroler Arduino UNO sebagai alat pengontrol, dimana sensor ultrasonik yang di pasang di atas pintu irigasi utama mengirimkan data yang diterima ke Arduino UNO dan motor servo sebagai penggerak membuka dan menutupnya pintu secara otomatis sesuai data yang dikirim oleh Arduino UNO.

\section{Metode}

Penelitian ini dilakukan terdiri beberapa tahapan yaitu, studi literatur dan observasi, analisis data, persiapan alat dan bahan, desain, implementasi, pengujian. Analisis data yang baik sangat membantu untuk proses penyelesaian masalah dan menghasilkan suatu teknologi [11][12]. Diagram alir dari tahapan penelitian dapat dilihat pada Gambar 1.

Berdasarkan Gambar 1, berikut adalah penjabaran dari lima tahapan yang dilakukan:

A. Studi Literatur dan Observasi

Pada tahap ini, dilakukan studi literatur terlebih dahulu. Studi literatur dilakukan dengan memahami dan mempelajari konsep sistem kontrol irigasi yang hendak dibangun, yang kemudian pencarian solusi terhadap alat dan bahan yang dibutuhkan. Demi tercapainya kegunaan pada sistem yang dikembangkan, dilakukan juga observasi secara langsung di lahan tani untuk memperoleh spesifikasi alat yang dibutuhkan secara tepat.

B. Persiapan Alat dan Bahan

Berdasarkan hasil tahapan sebelumnya, pada tahap ini dilakukan proses mempersiapkan kebutuhan alat dan bahan dalam membangun alat. Berikut adalah beberapa komponen alat yang dibutuhkan:

1. Komputer/laptop, digunakan dalam membuat program yang kemudian diunggah dengan memanfaatkan software Arduino IDE ke mikrokontroler Arduino.

2. Bor, digunakan untuk membuat lubang pada talang dan paralon sebagai tempat keluar masuknya air.
3. Solder, digunakan untuk menggabungkan komponen-komponen agar saling terhubung sesuai dengan rancangan yang dibuat.

4. Timah Solder, berbentuk seperti kawat yang akan dilelehkan dengan solder sebagai perekat untuk tiap-tiap komponen.

5. Pisau Cutter, digunakan untuk memotong talang dan paralon agar sesuai dengan ukuran.

Selanjutnya, bahan-bahan yang dibutuhkan adalah sebagai berikut:

1. Arduino UNO R3, merupakan board berbasis mikrokontroler pada ATmega328 [13] yang pada penelitian ini digunakan sebagai pusat kontrol dalam sistem pembukaan dan penutupan katup untuk pengairan/irigasi.

2. Liquid Crystal Display (LCD) $16 \times 2$, merupakan salah satu jenis display elektronik yang dibuat menggunakan teknologi CMOS logic [14] yang dalam penelitian ini dimanfaatkan untuk menampilkan informasi sistem.

3. Sensor Ultrasonik HCSRF-04, memiliki prinsip kerja, yaitu transmitter memancarkan seberkas sinyal ultrasonik $(20 \mathrm{KHz})$ yang berbentuk pulsa, kemudian jika didepan HCSFR-04 ada objek padat maka receiver akan menerima pantulan sinyal ultrasonik tersebut Receiver akan membaca lebar pulsa (dalam bentuk PWM) yang dipantulkan objek dan selisih waktuk pemancaran. Dengan pengukuran tersebut, jarak objek didepan sensor dapat diketahui yang dalam penelitian ini adalah debit air.

4. Motor Servo, menggunakan sistem umpan balik tertutup, di mana posisi dari motor akan diinformasikan kembali ke rangkaian kontrol yang ada di dalam motor servo [10]. Pada penelitian ini, motor servo digunakan sebagai penggerak bagi katup untuk terbuka dan tertutup dalam sistem irigasi.

5. Adaptor $12 \mathrm{~V}$, digunakan untuk menurunkan tegangan AC 22 Volt menjadi kecil antara 3 volt sampai 12 volt sesuai kebutuhan alat elektronika.

6. Jumper Wire, kabel yang digunakan sebagao penghubung antara perangkat sensor ataupun breadbord dengan mikrokontroler dan media transmisi penghantar listrik maupun signalsignal dari sensor, kemudian diterjemahkan oleh mikrokontroler itu sendiri. 


\section{Desain}

Pada tahap ini dilakukan perancangan terhadap alat yang hendak dibangun. Untuk memperoleh hasil yang maksimal diperlukan rancangan yang baik dengan memperhatikan sifat dan karakteristik dari tiap-tiap komponen yang digunakan, agar kerusakan komponen dapat dihindari. Dalam tahap perancangan terdiri dari beberapa tahapan yaitu perancangan blok diagram, komponen-komponen elektronika, dan rangkaian mekanika.

Perancangan diagram blok merupakan penjabaran cara kerja alat secara keseluruhan mulai dari input, proses hingga output. Dalam diagram blok ini hanya terdapat hubungan jalur anatara blok-blok saja, tetapi tiap masingmasing blok terdapat komponen utama dan komponen pendukung. Pada Gambar 2, ditujukkan diagram blok dari mikrokontroler alat yang dibangun.

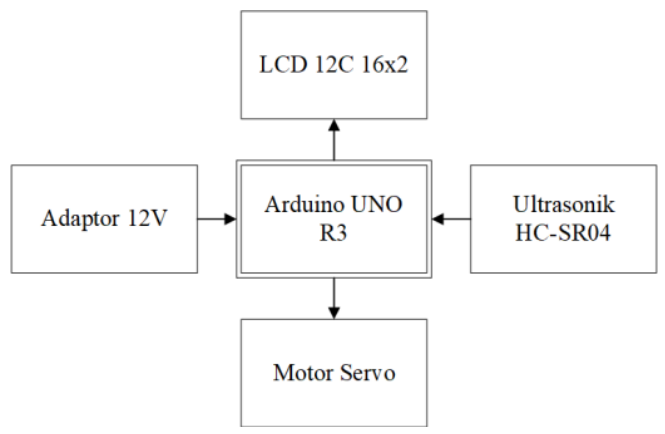

Gambar 2. Diagram blok

Berdasarkan diagram blok pada Gambar 2, dapat dijelaskan fungsi masing-masing blok sebagai berikut:

- Adaptor $12 \mathrm{~V}$ digunakan untuk memberikan tegangan ke arduino dan komponen lainnya yang terhubung ke arduino.

- Mikrokontroler arduino digunakan untuk mengontrol semua komponen baik itu komponen input dan komponen output.

- Sensor ultrasonik digunakan untuk mengukur jarak air.

- Motor servo digunakan untuk penggerak pintu irigasi.

- LCD I2C 16x2 digunakan sebagai monitor yang akan menampilkan nilai jarak air.

Perancangan komponen sensor ultrasonik dilakukan untuk menggambarkan penempatan serta bagaimana penghubungan sensor ultrasonik terhadap Arduino UNO. Sensor ultrasonik bekerja dengan membaca data jarak air. Selanjutnya ultrasonik mengirim data jarak air ke arduino untuk ditampilkan ke layar LCD. Rancangan desain sensor ultrasonik ditunjukkan pada Gambar 3.

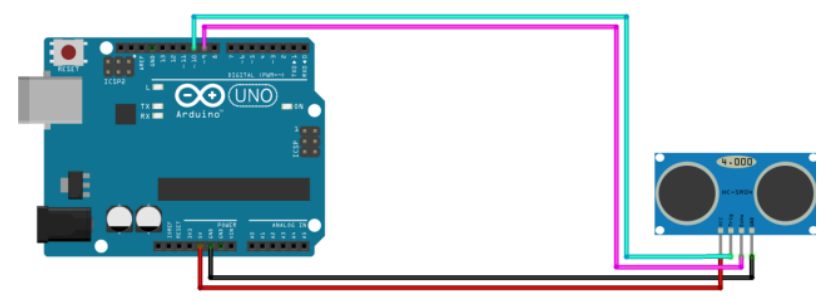

Gambar 3. Desain komponen sensor ultrasonik
Perancangan komponen motor servo dilakukan untuk menggambarkan penempatan serta bagaimana penghubungan motor servo terhadap Arduino UNO, yang dapat dilihat pada Gambar 4. Motor servo merupakan komponen yang digunakan untuk menggerakkan pintu irigasi. Motor servo bergerak secara otomatis sesuai dengan kondisi air pada alat simulasi pintu irigasi.

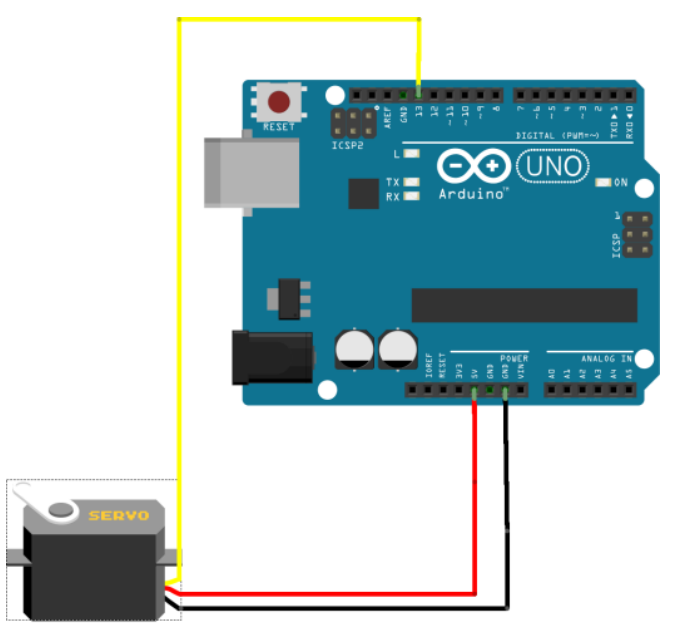

Gambar 4. Desain komponen motor servo

Perancangan komponen LCD dilakukan untuk menggambarkan penempatan serta bagaimana penghubungan LCD terhadap Arduino UNO, yang ditunjukkan pada Gambar 5. LCD (Liquid Crystal Display) adalah jenis media tampilan atau Display dari bahan cairan kristal sebagai penampil utama. LCD I2C $16 \times 2$ dapat menampilkan sebanyak 32 karakter yang terdiri dari 2 baris dengan tiap baris menampilkan 16 karakter. Di perancangan alat ini, LCD berfungsi untuk menampilkan data jarak air.

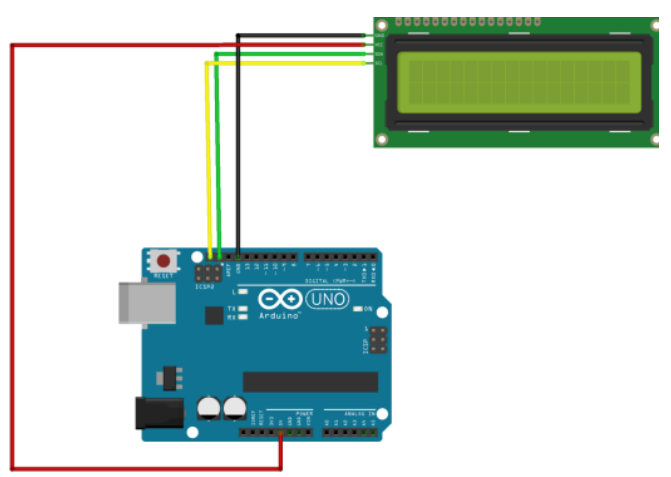

Gambar 5. Desain komponen LCD

Perancangan rangkaian mekanika merupakan perancangan rangkaian keseluruhan alat yang terdiri dari empat elemen penting yang saling terintegrasi. Elemenelemen penting tersebut yaitu rangkaian input, rangkaian pengendali, rangkaian output dan juga software program yang saling terintegrasikan. Rangkaian yang terdiri dari komponen-komponen elektronika baik berupa input dan output yang dibutuhkan oleh mikrokontroler agar dapat berfungsi dengan baik. Rangkaian keseluruhan alat dapat dilihat pada Gambar 6. 


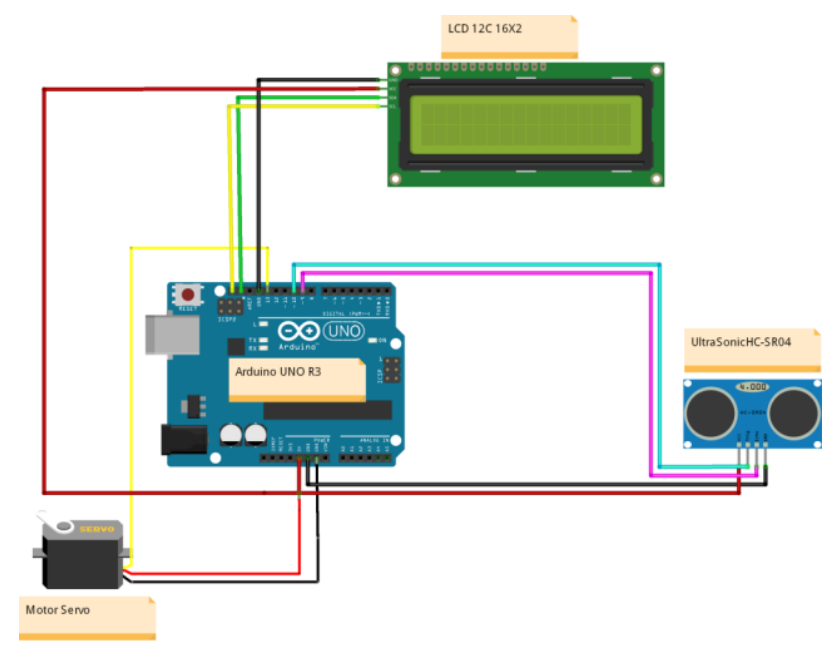

Gambar 6. Desain rangkaian mekanika

Dari peracangan keseluruhan alat pada Gambar 6 dapat dijelaskan sebagai berikut:

- Sensor ultrasonik terdapat 4 kabel (merah, biru, pink dan hitam) yang akan disambungkan ke arduino. Masing-masing ada VCC, TRIG, ECHO dan GND. Pin VCC akan disambungkan ke pin 5v dan VCC di LCD I2C 16x2, pin TRIG disambungkan ke pin 10 arduino, pin ECHO disambungkan ke pin 9 arduino dan pin GND disambungkan ke GND arduino.

- Motor servo terdapat 3 kabel (hitam, merah dan kuning) yang akan disambungkan ke arduino. Masing-masing ada GND, VCC dan data. Pin GND disambungkan ke pin GND arduino, pin VCC disambungkan ke pin $5 \mathrm{v}$ arduino dan pin data disambungkan ke pin 13 arduino.

- LCD I2C 16x2 terdapat 4 kabel (hitam, merah, hijau dan kunging) yang akan disambungkan ke arduino. Masing-masing ada GND, VCC, SDA dan SCL. Pin GND disambungkan ke GND arduino, pin VCC disambungkan ke 5v arduino, pin SDA disambungkan ke SDA arduino dan pin SCL disambungkan ke SCL arduino

\section{Implementasi}

Desain yang telah dihasilkan pada tahap sebelumnya, kemudian dilakukan penggabungan secara nyata pada komponen-komponen elektronika hingga menjadi satu pada rangkaian mekanika. Selanjutnya, dilakukan penerapan logika pengontrolan ke dalam sistem melalui pemrograman pada Software Arduino IDE. Arduino IDE adalah perangkat lunak yang digunakan untuk menyisipkan program-program yang berisi perintah dan diunggah ke mikrokontroler untuk pengaplikasiannya. Penulisan kode program dilakukan untuk memberikan instruksi-instruksi menggunakan bahasa pemrograman $\mathrm{C}$ yang bertujuan untuk menjalakan sistem agar dapat berkerja sesuai kode program yang telah diisikan kedalam sebuah Arduino. Tanpa kode program, sistem tidak dapat bekerja dikarenakan kode program adalah bagian yang paling utama dalam membangun sebuah alat.

E. Pengujian
Pengujian pada alat ini meliputi pengujian setiap blok maupun pengujian secara keseluruhan. Pengujian setiap blok ini dilakukan untuk menentukan letak kesalahan dan mempermudah dalam analisis mikrokontroler bila alat tidak bekerja sesuai rancangan.

\section{Hasil dan Pembahasan}

Sistem pengontrol irigasi secara otomatis dibangun menggunakan Arduino UNO (sebagai pusat kontrol), sensor ultrasonik HCSRF-04 (sebagai pendeteksi debit air), serta beberapa komponen elektronika lainnya (sebagai penunjang kesatuan alat). Alat yang telah dibangun dapat dilihat pada Gambar 7.

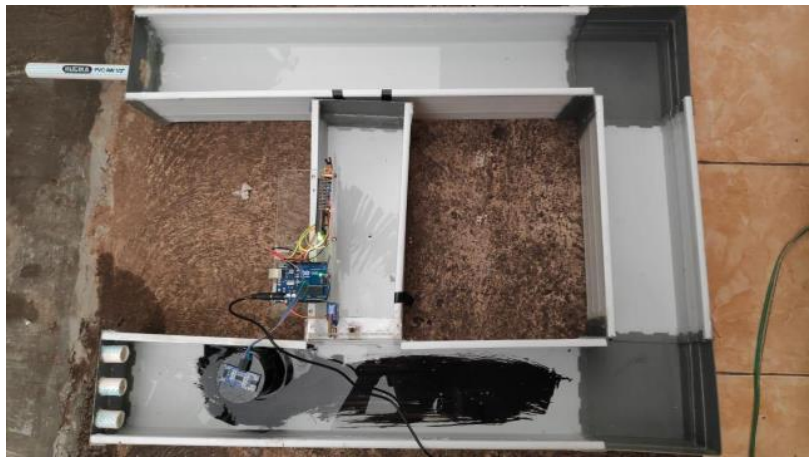

Gambar 7. Sistem pengontrol irigasi otomatis menggunakan Arduino UNO

Sistem yang telah dibangun pada Gambar 7 memiliki alur proses sebagai berikut:

- Pada awal sistem akan mulai memproses komponen untuk instalasi sensor ultrasonik.

- Sensor ultrasonik membaca jarak air dan mengirim data ke arduino.

- Kemudian sensor ultrasonik mengirimkan data ke arduino, dan memproses ke motor servo.

- Jika jarak air dengan sensor ultrasonik lebih dari 10 $\mathrm{cm}$, maka motor servo terbuka.

- Jika jarak air dengan sensor ultrasonik $7 \mathrm{~cm}$, maka motor servo menutup $1 / 2$.

- Jika jarak air dengan sensor ultrasonik kurang dari 5 $\mathrm{cm}$, maka motor servo akan menutup total.

Dalam menunjang keberhasilan alur proses tersebut, pada penelitian ini dilakukan beberapa pengujian. Mulamula pengujian dilakukan dengan terpisah, mulai dari komponen-komponen (LCD 16x2 karakter, motor servo, dan sensor ultrasonik) yang digunakan dalam perancangan alat ini sehingga mendapatkan hasil yang diinginkan. Setelah itu pengujian dilanjutkan dengan pengujian dari keseluruhan rangkaian komponen mikrokontroler yang telah terpasang.

A. Pengujian LCD

Pada tahap ini dilakukan pengujian komunikasi mikrokontroler Arduino UNO dengan module LCD 16x2, pada alat ini module LCD 16x2 digunakan sebagai monitoring untuk mengetahui kondisi kerja sistem pemantauan lebih mudah. Serta untuk melihat ketinggian air yang akan ditampilkan pada LCD. Berikut adalah hasil pengujian LCD ditunjukkan pada Gambar 8. 


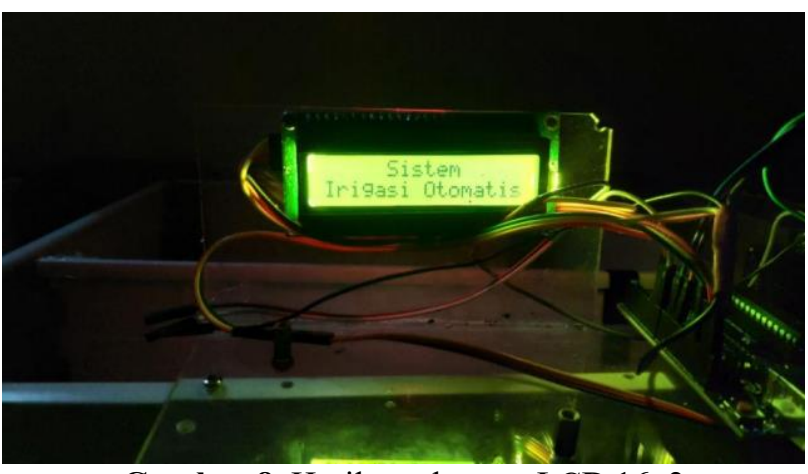

Gambar 8. Hasil pembacaan LCD 16x2

\section{B. Pengujian Motor Servo}

Pengujian motor servo digunakan untuk mengatur buka dan tutupnya secara otomatis sesuai yang sudah di atur. Berikut adalah hasil dari pengujian motor servo yang dapat dilihat pada Gambar 9.

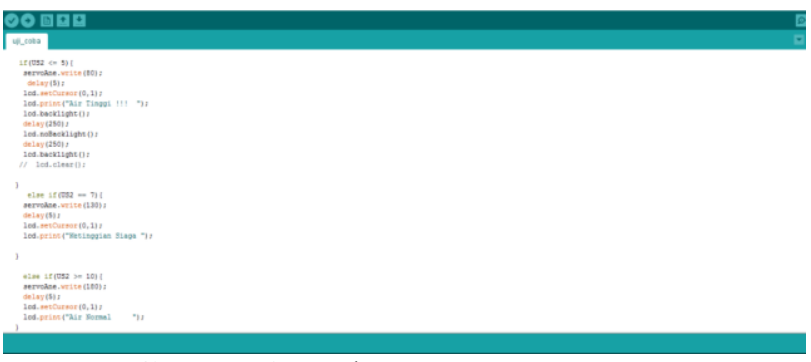

Gambar 9. Kode program motor servo

\section{Pengujian Sensor Ultrasonik}

Pengujian sensor ultrasonik ini bekerja berdasarkan pantulan gelombang untuk mendeteksi keberadaan suatu objek atau benda tertentu yang berada didepan sensor ultrasonik. Berikut adalah hasil dari pengujian dari sensor ultrasonik yang ditunjukkan pada Gambar 10.

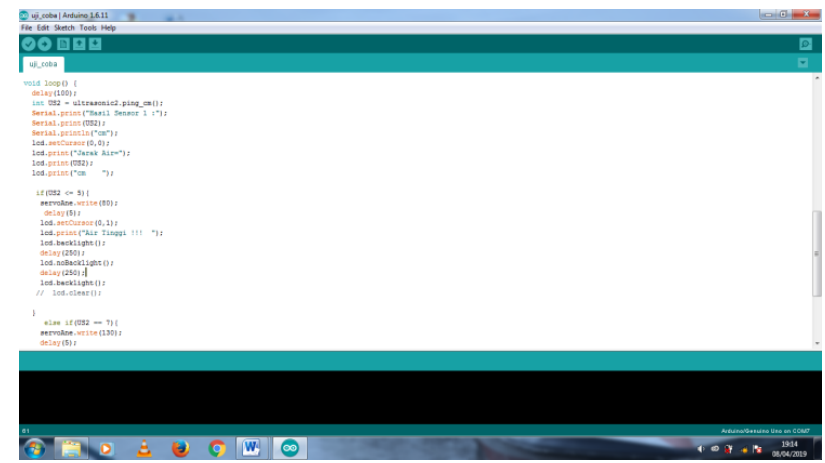

Gambar 10. Pengujian program sensor ultrasonik

Hasil dari pengujian yang dilakukan pada Gambar 10 dapat dilihat pada Tabel 1.

Tabel 1. Hasil pengujian sensor ultrasonik

\begin{tabular}{clc}
\hline No. & \multicolumn{1}{c}{ Jarak Air } & \multicolumn{1}{c}{ Keterangan } \\
\hline 1 & $\geq 10 \mathrm{~cm}$ & Pintu irigasi terbuka $3.5 \mathrm{~cm}$ \\
2 & $7 \mathrm{~cm}$ & Pintu irigasi tertutup $2 \mathrm{~cm}$
\end{tabular}

$3 \leq 5 \mathrm{~cm} \quad$ Pintu irigasi tertutup total

D. Pengujian Kesatuan Alat

Dari hasil pengujian alat secara keseluruhan, dapat disimpulkan bahwa jika jarak permukaan air ke sensor ultrasonik lebih dari sama dengan $10 \mathrm{~cm}$, maka pintu irigasi terbuka $3.5 \mathrm{~cm}$ dari bawah permukaan air. Sedangkan jika jarak air mencapai $7 \mathrm{~cm}$ dari permukaan air, maka pintu irigasi tertutup $2 \mathrm{~cm}$ dan jika jarak air mencapai kurang dari sama dengan $5 \mathrm{~cm}$ dari permukaan air, maka pintu irigasi akan tertutup total. Ketiga hasil pengujian tersebut dapat dilihat pada Gambar 11 hingga Gambar 13.

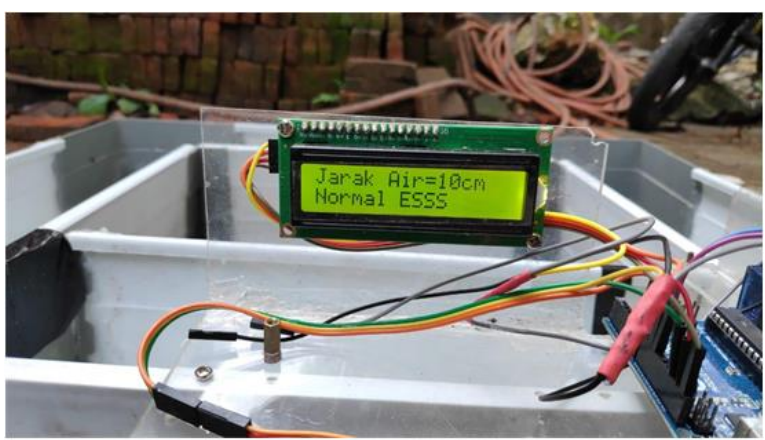

(a)

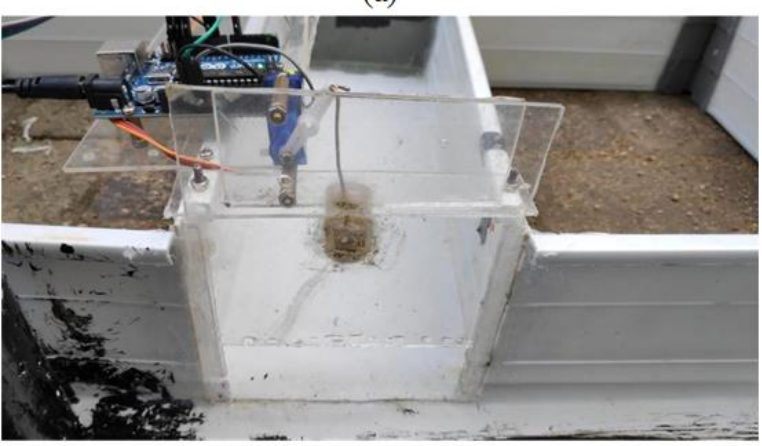

(b)

Gambar 11. Pengujian (a) jarak air $\geq 10 \mathrm{~cm}$ membuat (b) pintu irigasi terbuka $3.5 \mathrm{~cm}$

Gambar 12. Pengujian (a) jarak air $7 \mathrm{~cm}$ membuat (b) pintu irigasi tertutup $2 \mathrm{~cm}$ 


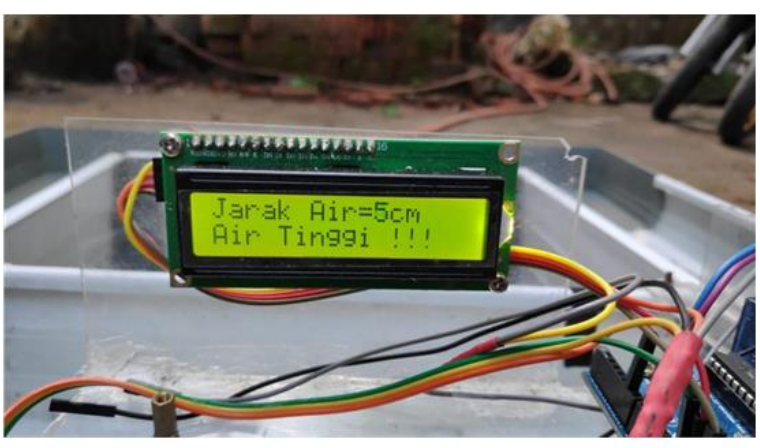

(a)

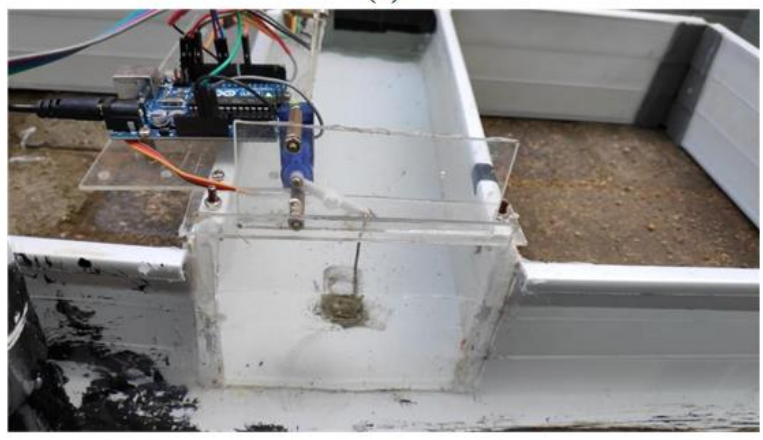

(b)

Gambar 12. Pengujian (a) jarak air $\leq 5 \mathrm{~cm}$ membuat (b) pintu irigasi tertutup total

\section{Kesimpulan dan Saran}

Penelitian ini berhasil membangun sistem pengontrol irigasi menggunakan mikrokontroler Arduino UNO, yang dapat digunakan untuk membantu pengairan pertanian kebun ataupun sawah lebih secara otomatis. Berdasarkan hasil pengujian dan analisis alat secara menyeluruh, diperoleh bahwa, 1) Dengan menggunakan alat motor servo, pintu irigasi dapat membuka dan menutup secara otomatis sesuai jarak air dengan bantuan komponen sensor ultrasonik yang terhubung melalui mikrokontroler arduino uno, 2) Dengan menggunakan sensor ultrasonik sebagai alat pembaca jarak air. Pintu irigasi dapat bekerja (membuka dan menutup) secara otomatis dengan mengirimkan data yang diterima arduino untuk diproses, lalu motor servo akan bekerja sebagai penggerak pintu irigasi.

Adapun kajian yang dapat dilakukan untuk pengembangan selanjutnya, yaitu, 1) Penambahan sensor di beberapa titik pintu irigasi percabangan, agar sistem dapat bekerja lebih sempurna dan lebih mendetail, 2) Proses monitoring tidak hanya ditampilkan pada layar LCD, tetapi juga dapat ditampilkan menggunakan web ataupun berbasis IoT agar dapat dikontrol lebih rinci jika alat bermasalah dan diperlukan penambahan indikator.

\section{Daftar Pustaka}

[1] A. R. Al Tahtawi, E. A. Andika dan W. N. Harjanto, "Desain awal pengembangan sistem kontrol irigasi otomatis berbasis node nirkabel dan Internet-ofThings," Jurnal Otomasi Kontrol dan Instrumentasi, vol. 10, no. 2, p.121, 2018.
[2] S. K. Saptomo, R. Isnaeni dan B. I. Setiawan, "Irigasi curah otomatis berbasis sistem pengendali mikro," Jurnal Irigasi, vol. 8, no. 2, pp.115-125, 2013.

[3] B. I. Setiawan dan S. K. Saptomo, "Sistem kontrol irigasi otomatis nirkabel," Jurnal Irigasi, vol. 9, no. 2, pp.108-114, 2014.

[4] A. Nurkholis, A. Riyantomo dan M. Tafrikan, "Sistem pakar penyakit lambung menggunakan metode forward chaining," Majalah Ilmiah Momentum, vol. 13, no. 1, 2017.

[5] A. Nurkholis, dan I. S. Sitanggang, "Optimalisasi model prediksi kesesuaian lahan kelapa sawit menggunakan algoritme pohon keputusan spasial," Jurnal Teknologi dan Sistem Komputer, vol. 8, no. 3, pp. 192-200, Jul. 2020. https://doi.org/10.14710/jtsiskom.2020.13657

[6] A. Nurkholis dan I. S. Sitanggang, "A Spatial Analysis Of Soybean Land Suitability Using Spatial Decision Tree Algorithm," In Proc. SPIE 11372, Sixth International Symposium on LAPAN-IPB Satellite, p. 113720I, 2019.

[7] Subari, H. A. Sofiyuddin dan B. I. Setiawan, "Pengembangan sistem irigasi terkendali menggunakan jaringan nirkabel, " Jurnal Irigasi, vol. 6, no. 1, pp.28-36, 2011.

[8] A. Tusi, B. I. Setiawan, H. A. Sofiyuddin, D. Rahmandani dan M. Muqorrobin, "Pengembangan pintu air irigasi glass fiber reinforced plastic," Jurnal Irigasi, vol. 5, no. 1, pp.57-67, 2010.

[9] H. A. Sofiyuddin, M. Muqorrobin, D. Rahmandani, A. Tusi dan B. I. Setiawan, "Pintu sorong tinjol berbahan fiberglass sebagai inovasi alat ukur debit dalam operasi irigasi," Jurnal Sumber Daya Air, vol. 8, no. 1, pp.27-38, 2012.

[10] I. K. Gunawan, A. Nurkholis dan A. Sucipto, "Sistem monitoring kelembaban gabah padi berbasis Arduino," Jurnal Teknik dan Sistem Komputer, vol. 1, no. 1, pp. 1-7, 2020.

[10] D. Alita, S. Priyanta dan N. Rokhman,"Analysis of Emoticon and Sarcasm Effect on Sentiment Analysis of Indonesian Language on Twitter," Journal of Information Systems Engineering and Business Intelligence, vol. 5, no. 2, pp. 100-109, 2019.

[11] H. Sulistiani, M. Miswanto, D. Alita dan P. Dellia, "Pemanfaatan Analisis Biaya dan Manfaat Dalam Perhitungan Kelayakan Investasi Teknologi Informasi," Edutic-Scientific Journal of Informatics Education, vol. 6, no. 2, 2020.

[12] S. Samsugi dan A. Burlian, "Sistem penjadwalan pompa air otomatis pada aquaponik menggunakan mikrokontrol Arduino UNO R3," Prosiding Semnastek, vol. 1, no. 1, 2019.

[13] S. Samsugi, Ardiansyah dan A. Suwantoro, "Pemanfaatan Peltier dan Heater Sebagai Alat Pengontrol Suhu Air Pada Bak Penetasan Telur Ikan Gurame," Conference on Information Technology, Information System and Electrical Engineering, pp. 295-299, 2016 